\title{
Oxytocin Receptor Gene (OXTR) and Deviant Peer Affiliation: A Gene-Environment Interaction in Adolescent Antisocial Behavior
}

\author{
Iro Fragkaki $\mathbb{1}^{1} \cdot$ Maaike Cima ${ }^{1} \cdot$ Maaike Verhagen $^{1} \cdot$ Dominique F. Maciejewski $^{2} \cdot$ Marco P. Boks $^{3} \cdot$ \\ Pol A. C. van Lier ${ }^{4}$ Hans M. Koot ${ }^{2,4}$ - Susan J. T. Branje ${ }^{5} \cdot$ Wim H. J. Meeus ${ }^{5,6}$
}

Received: 30 July 2018 / Accepted: 24 September 2018 / Published online: 12 October 2018

(c) The Author(s) 2018

\begin{abstract}
Although the oxytocin receptor gene $(O X T R)$ is involved in aggression and social affiliation, it has not been examined in gene-environment interaction studies. This longitudinal study examined the effect of genetic variants in OXTR and its geneenvironment interaction with perceived deviant peer affiliation in the trajectories of antisocial behavior in 323 adolescents (182 males) from 13 to 18 years. Annual assessments of reactive and proactive aggression, delinquency, and friends' delinquency, as well as DNA at age 17 were collected. Gene-based tests yielded no main effect of OXTR, but revealed a significant gene-environment interaction in proactive aggression and delinquency. Variation in the OXTR might affect the influence of deviant peer affiliation on antisocial behavior, contributing to a better understanding of individual differences in antisocial behavior.
\end{abstract}

Keywords Oxytocin receptor gene $\cdot$ Antisocial behavior $\cdot$ Deviant peer affiliation $\cdot$ Gene-environment interaction

\section{Introduction}

Antisocial behavior is among the most common reasons for referral to mental health services in adolescence and externalizing disorders often leads to detrimental long-term consequences (Erskine et al. 2016; Hacker et al. 2014).

Iro Fragkaki

i.fragkaki@pwo.ru.nl

1 Behavioural Science Institute, Radboud University, Montesorilaan 3, 6525 HR Nijmegen, The Netherlands

2 EMGO Institute for Health and Care Research, VU University Medical Center, Van der Boechorststraat 7, 1081 BT Amsterdam, The Netherlands

3 Department of Psychiatry, Brain Center Rudolf Magnus, University Medical Center Utrecht, Heidelberglaan 100, 3584 CX Utrecht, The Netherlands

4 Department of Clinical, Neuro and Developmental Psychology, VU University Amsterdam, De Boelelaan 1105, 1081 HV Amsterdam, The Netherlands

5 Department of Youth and Family, Faculty of Social and Behavioural Sciences, Utrecht University, Padualaan 14, 3584 CH Utrecht, The Netherlands

6 Department of Developmental Psychology, Tilburg University, Warandelaan 2, 5037 AB Tilburg, The Netherlands
Antisocial behavior is a multidimensional construct that includes a broad range of behaviors, mainly aggression and delinquency (Morizot and Kazemian 2015). In an effort to shed light on the etiology of antisocial behavior, researchers have revealed the role of genetic (explaining $40-60 \%$ of the variance) and non-shared environmental factors (explaining $30 \%$ of the variance) (Ferguson 2010; Tuvblad et al. 2011; Vitaro et al. 2015). Non-shared environmental factors refer to the environment that is not shared by siblings in a family, such as peer relations, differential parental treatment, accidents, or health issues. Shared and non-shared environmental factors have been thoroughly examined in relation to antisocial behavior and the important role of family and peer relations has been established (Assink et al. 2015). Research has also focused on identifying specific genes that contribute to the development of antisocial behavior, indicating that a region in chromosome $2(2 \mathrm{p} 12)$ and variation within AVPR1A might be associated with antisocial behavior (Pappa et al. 2016). There is also growing evidence on the effects of gene-environment interactions between specific genes and environmental factors on antisocial behavior, focusing, among others, on deviant peer affiliation, as it is one of the stronger predictors of adolescent antisocial behavior (Vitaro et al. 2015). However, there is a lack of research on potential gene-environment interaction effects between the oxytocin receptor gene (OXTR) and deviant 
peer affiliation in antisocial behavior, despite OXTR's association with antisocial behavior as well as social affiliation and bonding.

The OXTR gene is the encoded receptor for the neuropeptide oxytocin, which is involved in social-affective behaviors, such as prosocial behavior, social affiliation, attachment, and pair bonding (Lee et al. 2009). Experimental studies have indicated that intranasal administration of oxytocin enhances empathy, emotion recognition, trust, and generosity, and reduces stress reactivity (Guastella and MacLeod 2012; Veening and Olivier 2013). Importantly, this effect was more pronounced in individuals with socialaffective deficits (Bartz et al. 2011). Abnormal oxytocin levels have also been found in patients with ADHD, conduct disorder, and psychopathy, but the results have been contradictory, demonstrating both higher and lower oxytocin levels in patients compared to controls (see for a review Fragkaki et al. 2017).

Furthermore, the OXTR gene is expressed in the brain and several other tissues, but its anatomical distribution varies considerably across species and affects the social organization of each species (see for a review Vaidyanathan and Hammock 2016). Developmental experiences and epigenetics can alter $O X T R$ expression in adulthood leading to impairments in social behavior. OXTR expression and distribution differ across development and it has been proposed that "OXTR may be a developmental plasticity gene that serves as a transducer of the social environment to finetune the experience-dependent plasticity of the social brain" (Vaidyanathan and Hammock 2016). More specifically, a transient profile of OXTR mRNA has been observed in the human neocortex and it has been argued that oxytocin plays a crucial role in the processing of socially contingent sensory information in the neocortex (Vaidyanathan and Hammock 2016). Indeed, genetic studies have shown associations between OXTR and social behavior, pair bonding, social cognition, social interaction, and social support, especially for the single nucleotide polymorphisms (SNPs) rs53576 and rs2254298, although the results were inconsistent (Bakermans-Kranenburg and Van IJzendoorn 2013; Ebstein et al. 2012). Based on these findings and taking into account that individuals with antisocial behavior are characterized by social-affective deficits, research has explored whether antisocial behavior might be related to variations within the $O X T R$.

Several studies have addressed this question by examining $O X T R$ variations in healthy and antisocial individuals. Findings from healthy samples revealed significant effects of OXTR polymorphisms on antisocial behavior in young males (Hovey et al. 2015; LoParo et al. 2016). Particularly, the $\mathrm{C}$ allele of the rs 4564970 and the AA genotype of the rs7632287 were related to aggression and rs7632287 AA was associated with delinquency in boys only in a large sample of 2372 individuals and a replication sample of 1232 individuals, including adolescents and young adults (16-20 years) (Hovey et al. 2015). A 6-factor model for OXTR was also associated with aggression and interacted with alcohol in 235 males aged 18-32 years in response to aggression provocation (LoParo et al. 2016). Another study showed that male carriers of the A allele of rs 1042778 had higher right amygdala reactivity in response to angry faces which was related to higher levels of antisocial behavior in a sample of 406 healthy young adults aged 18-22 years (Waller et al. 2016). Overall, the evidence so far suggested an association between genetic variations in OXTR and antisocial behavior in healthy samples.

Previous studies on clinical samples with antisocial behavior have also yielded significant associations with OXTR polymorphisms. In specific, the $\mathrm{C}$ allele of rs1042778 as well as the haplotypes CG of rs1042778 and rs6770632, and CT of rs1042778 and rs53576 were more prevalent in aggressive boys, whereas the A allele for rs6770632 was more prevalent in aggressive girls in 160 children and adolescents with disruptive disorders compared to 160 healthy adults (Malik et al. 2012). However, the findings did not survive multiple correction testing when compared to 182 healthy children (Malik et al. 2014). A recent study found increased conduct problems at age 15 in rs $53576 \mathrm{G}$ carriers in a sample of 404 adolescents with high levels of maternal depression (Smearman et al. 2015). In contrast, another study examined the effects of 10 single nucleotide polymorphisms in 1750 adolescents with substance and behavioral problems and found no significant effects of the 10 single nucleotide polymorphisms in relation to conduct disorder (Sakai et al. 2012). It is noteworthy that the aforementioned studies showed various OXTR polymorphisms in relation to antisocial behavior, but the results did not consistently support the central role of specific single nucleotide polymorphisms. These mixed findings suggest the contribution of small effects of several single nucleotide polymorphisms rather than the role of one specific single nucleotide polymorphism in antisocial behavior.

Additionally, the complexity of antisocial behavior should be taken into account in the interpretation of the findings. Although aggression and delinquency are central components of antisocial behavior, there are more specific subtypes, such as types of aggression and psychopathic traits. Particularly, two types of aggression are often distinguished, reactive and proactive aggression. Reactive aggression is an impulsive response to threat, provocation, or frustration and it is accompanied with anger, whereas proactive aggression is planned and driven by the achievement of a goal or a reward (Vitaro et al. 2006). These two types of aggression have distinct characteristics and are related to different social, cognitive, emotional, and 
physiological processes and outcomes (Hubbard et al. 2010).

More specifically, reactive aggression is associated with anger, peer rejection, internalizing problems, paranoid personality traits, bad quality of parent-child relationship, lower number of friends, and higher physiological arousal after provocation (Hubbard et al. 2010). In contrast, proactive aggression is not related to anger, internalizing problems, or bad quality of parent-child relationship but rather the lack of parental monitoring. It is characterized by a lack of physiological arousal in response to provocation (Hubbard et al. 2010) and it is linked to antisocial but not paranoid personality traits (Lobbelstael et al. 2015). In addition, distinct deficiencies in social information processing have been found in reactive and proactive aggression, indicating that reactive aggression is linked to impairments in encoding and interpretation of cues, whereas proactive aggression is linked to impairments in clarification of goals, response access, and response decision (Kempes et al. 2005). Most importantly, although both types are influenced by genetic and environmental factors, the stability of proactive aggression over time is more strongly explained by genetic factors than the stability of reactive aggression (Tuvblad and Baker 2011). In addition, proactive aggression is behaviorally and genetically linked to callousunemotional traits and psychopathy (Bezdjian et al. 2011; Cima and Raine 2009), which are characterized by shallow emotion, lack of empathy, shame, or guilt and are related to more severe antisocial behavior and stronger biological underpinnings (Frick et al. 2014). Overall, distinct characteristics between reactive and proactive aggression have been revealed, underscoring the different processes associated with each type and suggesting a stronger biological background for proactive aggression compared to a more environmental background for reactive aggression.

Taken together, the findings, although promising, do not provide a clear picture of the genetic contribution of OXTR in antisocial behavior. First, the aforementioned studies showed various risk alleles in different types of antisocial behavior. Second, previous studies did not systematically include several types of antisocial behavior, raising the question of whether $O X T R$ variations are linked to antisocial behavior as a construct or to specific types of antisocial behavior.

In a similar vein, the gene-environment interaction between $O X T R$ and deviant peer affiliation has not been explored yet. Considering that $O X T R$ is related to social affiliation and bonding, and that peer affiliation is a fundamental expression of social relationships in adolescence, it is crucial to explore whether $O X T R$ interacts with deviant peer affiliation in the development of antisocial behavior. Deviant peer affiliation has been widely established as one of the strongest non-shared environmental predictors of antisocial behavior in adolescence (Dishion et al. 1995; Vitaro et al. 2015). However, it is also influenced by genetic factors, especially in adolescence (Connolly et al. 2015; Vitaro et al. 2015). In addition, there is increased support for gene-environment interactions in antisocial behavior. Gene-environment interaction studies explain their findings in terms of the diathesis stress model (Zuckerman 1999) or the differential susceptibility model (Belsky and Pluess 2009). According to the diathesis-stress model, adolescents with a genetic predisposition toward antisocial behavior are more likely to develop such a behavior when they affiliate with deviant peers (Zuckerman 1999). According to the differential susceptibility model, adolescents with a genetic vulnerability might exhibit more positive behaviors when interacting with a positive environment but more negative behaviors when interacting with a negative environment (Belsky and Pluess 2009). Several previous studies revealed gene-environment interactions in antisocial behavior for several genes, but the results were inconsistent (Vitaro et al. 2015).

It is argued that the investigation of a gene-environment interaction between $O X T R$ and deviant peer affiliation is crucial due to $O X T R$ 's involvement not only in antisocial behavior but also in social affiliation, which is under ongoing development during adolescence in form of peer relationships. In an effort to understand the role of oxytocin in social behavior, it has been suggested that oxytocin might modulate the salience of social stimuli in the environment and direct our attention toward them, leading to a better understanding of social cues and thus a more successful formation of social relations (Shamay-Tsoory and AbuAkel 2016). Another approach posits that oxytocin might be related to self-referential processing and interoception that may contribute to the development of empathy and promote in-group survival (Hurlemann and Scheele 2016). Additionally, as mentioned above, oxytocin is involved in the development of the social brain (Vaidyanathan and Hammock 2016). Recent animal studies showed that oxytocin release is increased in the ventral tegmental area during social interactions, which in turn increases the activity of dopamine neurons that are involved in social reward, emphasizing the role of oxytocin in social behaviors (Hung et al. 2017). Therefore, oxytocin seems to have a contributing part in the development of social-affective behaviors and especially social relationships.

It is widely known that during adolescence peers exert a great influence on each other and adolescents tend to create in-groups with close friends and conform to the behavioral norms of the group (Steinberg and Morris 2001). Consequently, adolescents who affiliate with deviant peers tend to exhibit also deviant behaviors in order to conform to their friends' behavior and maintain their peer group. Speculatively, a potential gene-environment interaction of $O X T R$ 
and deviant peer affiliation might be driven by OXTR's role in the development of the social brain, prosocial behavior, and social affiliation that can interact with the social bonds with peers leading to distinct patterns in antisocial behavior.

\section{Current Study}

The purpose of this longitudinal study was to investigate the association between OXTR polymorphisms and the developmental trajectories of antisocial behavior as well as the gene-environment interaction with perceived deviant peer affiliation in these trajectories in a sample of adolescents from 13 to 18 years. Specifically, the main effect of OXTR and the proposed gene-environment interaction were assessed in three main aspects of antisocial behavior: reactive aggression, proactive aggression, and delinquency. Importantly, this study has a longitudinal design following youth from early adolescence (age 13) to late adolescence (age 18). This design allows the examination of the development and stability of antisocial behavior across adolescence and can shed light on whether the proposed geneenvironment interaction leads to distinct trajectories of antisocial behavior over the course of adolescence. Taken together, based on OXTR's role on social and antisocial behaviors as well as previous findings supporting a main effect of OXTR and perceived deviant affiliation on antisocial behavior, it was hypothesized that OXTR would influence the developmental trajectories of antisocial behavior and that there would be an interaction between OXTR and perceived deviant peer affiliation. Importantly, it was explored whether OXTR interacted with perceived deviant peer affiliation on all aspects of antisocial behavior or it was specific to proactive aggression, reactive aggression, or delinquency.

Last but not least, due to previous inconsistent findings on the specific OXTR polymorphisms as well as recent directions underscoring the limitations of SNP-based tests, gene-based tests were performed to examine the direct and interaction effects. Gene-based tests increase the detectability of associations by aggregating small effects, reducing the number of tests and thus the need for multiple testing correction, and avoiding canceling signals with opposite etiological effects (Tzeng et al. 2011). That way, the amount of genetic variation and the power to detect associations are increased, especially in moderate sample sizes (Tzeng et al. 2011). They also allow the inclusion of covariates to control for the effect of known predictors of adolescent antisocial behavior, such as gender and socioeconomic status (Loeber and Farrington 2000; Murray and Farrington 2010). Therefore, this approach has several benefits compared to SNP-based tests that investigate small individual effects of many single nucleotide polymorphisms and required correction for multiple testing. The use of gene-based testing is common in genome-wide association studies and is recently expanding on the effects of specific genes in various phenotypes in smaller studies (LoParo et al. 2016; Tzeng et al. 2011; Zhao et al. 2015). It's important to note though that gene-based tests are not direction tests and do not provide specific directionality of the proposed interactions as they aggregate the effects of several different single nucleotide polymorphisms, each of which has its own positive or negative loading (LoParo et al. 2016; Tzeng et al. 2011). Overall, this study explored the interaction between OXTR and perceived deviant peer affiliation on antisocial behavior over the course of adolescence using a longitudinal design and gene-based testing.

\section{Method}

\section{Participants}

The sample included in this study is a subsample of an ongoing longitudinal project, the Research on Adolescent Development And Relationships-young cohort study (RADAR-y). The project prospectively follows 497 Dutch families in order to investigate normal and abnormal adolescent development and the role of parents and peers with a specific focus on delinquency development. To achieve this goal, an increased number of adolescents at risk of externalizing problems were included (as identified by a $\mathrm{T}$ score $\geq 60$ on the Teacher's Report Form at age 11; Achenbach 1991). The project has been conducted in accordance with the Declaration of Helsinki and has been granted Medical Ethical approval from the University Medical Center Utrecht. All participants and their parents provided written informed consent and received a financial compensation for their participation. A more detailed description of the recruitment of participants in the Research on Adolescent Development And Relationships-young cohort study (RADAR-y) can been found elsewhere (e.g., Maciejewski et al. 2015).

In this study, adolescents who participated in the first six annual waves with measurements of aggression, delinquency, delinquent behavior of their friends (index of perceived deviant peer affiliation), DNA samples (at Wave 5), and of European ancestry $(n=332)$ were included. Eight participants were excluded due to DNA contamination or DNA criteria for exclusion (see details in Genotyping). The final sample comprised 323 adolescents (182 males) with a mean age of $13.00(S D=.42)$ at the first wave and 18.00 $(S D=.42)$ at the sixth wave. The majority of the participants came from a medium or high socio-economic background $(93.7 \%$; at least one of the parents' jobs was classified as medium or high level) and approximately one 
third of the sample $(35.6 \%)$ was at risk of externalizing problems. The attrition rate was $4.6 \%$ in this sample over the six waves.

\section{Procedure}

Prior to the beginning of the study, the participants and their parents received detailed written information about the project and provided written informed consent. Home visits took place annually and trained research assistants administered a battery of questionnaires to the adolescents. The research assistants provided verbal instructions in addition to the written instructions for each questionnaire. Other research assistants performed the data entry to ensure anonymity of the participants. DNA samples were collected at Wave 5 and participants had to visit the university lab to provide blood samples (see details in Genotyping).

\section{Measures}

\section{Aggression}

Reactive and proactive aggression were measured in each wave with a short version (23-item) of the Self-report of Aggression and Social Behavior Measure (Linder et al. 2002; Morales and Crick 1998). The items are rated on a 7point Likert scale ranging from 1 (not at all true) to 7 (completely true). In this study only the total scores for proactive ( 8 items) and reactive ( 8 items) aggression were included to provide a more robust measurement of aggression and examine the specific hypotheses. Example items are "When someone makes me very angry, I push or punch that person" for reactive aggression and "I threaten to hurt others (hitting, kicking) to make them do what I want" for proactive aggression. A sum score of the items corresponding to each subscale for each wave was computed and higher scores indicated higher levels of proactive and reactive aggression. The distinct subscales of the measurement have shown good reliability and construct validity in previous studies (Ostrov and Houston 2008; Skripkauskaite et al. 2015). The Cronbach's alpha of proactive aggression ranged from .84 to .90 and the Cronbach's alpha of reactive aggression ranged from .84 to .88 across the six waves.

\section{Delinquency}

Delinquent behavior of the participants was assessed in each wave with the International Self-Report Delinquency scale (Junger-Tas et al. 1994). The scale includes 30 statements of delinquent behaviors, such as vandalism, theft, and selling stolen goods rated on a 5-point Likert scale $(0=$ never, $4=$ more than 10 times). A variety score was used, indicating how many different delinquent acts were committed by the participants instead of a frequency score, because the former is a more accurate indicator of severity of delinquency due to the disproportion of minor and serious offenses and their weight in frequency scores (Bendixen et al. 2003). The variety score was computed by recoding all 30 items into dichotomous (0/1) variables (i.e., never/at least once) and summing them for each wave. This type of measure has been frequently used with established psychometric properties (Junger-Tas and Marshall 1999). The Cronbach's alpha ranged from .76 to .89 across the six waves.

\section{Deviant peer affiliation}

Perceived peer delinquency (as an index of perceived deviant peer affiliation) was assessed annually with a 6-item scale in which the participants indicated how many of their friends committed various delinquent acts in the past three months, such as vandalism, theft under 5 euro, theft over 5 euro, assault, burglary, or robbery (Weerman and Smeenk 2005). The items are rated on a 3-point Likert scale from 1 (no one) to 3 (most/all of them). A sum score of all the items for each subscale was calculated and higher scores indicated higher levels of perceived peer delinquency. This scale has satisfactory one-dimensional factor structure and good reliability and construct validity in previous studies (Keijsers et al. 2012; Weerman and Smeenk 2005) and the Cronbach's alpha in this study ranged from .64 to .86 across the six waves. A mean score across the six waves was calculated to provide a robust measure of perceived peer delinquency and achieve convergence of the models.

\section{Genotyping}

The genotyping was performed with the Affymetrix 6.0 array (McCarroll et al. 2008) using DNA from the whole blood. The genotype calling was performed with the Birdseed 2 algorithm (Korn et al. 2008; McCarroll et al. 2008), with the Affymetrix 3.3 APT software on all samples simultaneously. Samples were removed in case the Affymetrix CQC was lower than 0.40, the genotyping calling rate was lower than 0.90 , the heterozygosity $F$ value was different from zero, or in case the DNA gender of the sample did not match the phenotype gender. Additionally, samples were removed if the 10 genetic principal components indicated a CEU ethnic outlier after projection of the study samples on the 1000 genomes reference sample. Fifty-three participants were identified as ethnic outliers and excluded from the analyses. Single nucleotide polymorphisms were filtered using Plink 1.07 (Purcell et al. 2007) based on the following criteria: No or incorrect mapping on 
Table 1 Markers of the five single-nucleotide polymorphism (SNPs) included in the study

\begin{tabular}{lllll}
\hline SNP & Position & H-W & MAF & Alleles \\
\hline rs1042778 & 879454 & 0.9217 & 0.36 & A:C \\
rs2254298 & 880222 & 0.3575 & 0.105 & A:C \\
rs53576 & 8880437 & 0.458 & 0.342 & C:A \\
rs4686302 & 880922 & 0.5709 & 0.124 & A:C \\
rs237915 & 881031 & 0.5575 & 0.274 & A:C \\
\hline
\end{tabular}

SNP single nucleotide polymorphisms, $H$ - $W$ Hardy-Weinberg equilibrium, $M A F$ minor allele frequency

Build 37 HG19 of the human genome, inconsistent calls in plate control samples with an error rate $>1 \%,<0.95$ genotyping rate, MAF $<0.01$, HWE $p<0.000001$. After this QC, all single nucleotide polymorphisms were strand aligned to the 1000 genomes Phase 1 June 2014 reference. The genotype data were subsequently phased with SHAPEIT V2.970 (Delaneau et al. 2013) and imputed to the 1000 genomes reference with IMPUTE 2.3.1 following standard protocols (van Leeuwen et al. 2015). Single nucleotide polymorphisms with imputation quality $R^{2}$ higher than 0.8 were used.

The oxytocin receptor gene (OXTR) is a 389-amino acid polypeptide with seven transmembrane domains and belongs to the class I G protein-coupled receptor family. The gene coding for OXTR is located on chromosome 3 (3p25), and has 3 introns and 4 exons (Gimpl and Fahrenholz 2001). It is $17 \mathrm{kbp}$ long and has 111 common single nucleotide polymorphisms. In this study, the following single nucleotide polymorphisms were included: rs1042778, rs2254298, rs53576, rs4686302, rs237915. These single nucleotide polymorphisms were selected due to their association with social behaviors and their relation to antisocial behavior in the previous studies described above. They are also all involved in the transcriptional regulation of $O X T R$ and thus play a role in the expression of the gene (Lee and Shatkay 2008). The rs2254298, rs53576, and rs237915 are located on introns, the rs1042778 is located on the 3' prime untranslated region, and the rs4686302 is nonsynonymous. The linkage disequilibrium (LD) and the Hardy-Weinberg (HW) equilibrium were assessed with Haploview (Barrett et al. 2005). There was high linkage disequilibrium between some single nucleotide polymorphisms (rs1042778 and rs2254298: $D^{\prime}=.84$; rs53576 and rs4686302: $D^{\prime}=.82 ; \quad$ rs4686302 and rs237915: $D^{\prime}=1$ ). The gene-based tests performed in this study take into account the high linkage disequilibrium of the single nucleotide polymorphisms. All single nucleotide polymorphisms were in Hardy-Weinberg equilibrium (all $p$ s > .05) (see Table 1).

\section{Analytic Strategy}

Two steps were followed to examine the main effects and the gene-environment interaction. First, latent growth curve models were fitted to estimate the developmental trajectories of reactive aggression, proactive aggression, and delinquency across the six annual waves using Mplus version 7.0 (Muthén and Muthén 1998-2015). The growth curves are estimated by the intercept (i.e., the initial level of antisocial behavior at wave 1) and the linear, quadratic, or cubic slopes (i.e., the change in antisocial behavior over time across the six waves). Maximum likelihood estimation with robust standard errors was selected to handle nonnormality and missing data. To estimate the fit of the models, the following fit indices were used: the root mean square error of approximation (RMSEA), the standardized root mean square residual (SRMR), the comparative fit index (CFI), and the Tucker-Lewis fit index (TLI). Values below .10 for the root mean square error of approximation and the standardized root mean square residual, and above .90 for the comparative fit index and Tucker-Lewis fit index are indicative of an acceptable fit (Browne et al. 1993; MacCallum et al. 1996). However, more strict cut-off values of $<.06$ for the root mean square error of approximation, $<.08$ for the standardized root mean square residual, and $>.95$ for the comparative fit index and TuckerLewis fit index have also been proposed for a good fit $(\mathrm{Hu}$ and Bentler 1999).

The trajectory of delinquency was evaluated with a twopart model due to a preponderance of zeros and the highly skewed distribution of delinquency scores. This model breaks down a variable into two parts, a dichotomous part that expresses the probability of an observed behavior (delinquency) occurring at each time point and a continuous part that expresses the amount of the observed behavior among participants who reported the occurrence of the observed behavior (variety of delinquent acts) using logtransformed values. In the continuous part, the participants who did not report committing a delinquent act were treated as missing, under the assumption that data are missing at random (MAR) (Muthén and Muthén 1998-2015). The first part of the model is estimated with a logistic growth function and the second part with a linear growth function. In order to identify the best fitting models, the growth curves of the probability and amount of delinquent acts were evaluated in two separate unconditional models. The model fit of the probability of committing a delinquent act (part 1) was assessed comparing a model including a linear and a quadratic growth factor. The addition of the quadratic slope improved the model fit $\left(\Delta \chi^{2}=23.131, p<.005\right)$. Considering that $\chi^{2}$ tests are affected by large sample sizes and that the mean and variance of the quadratic slope were not 
Table 2 Means and standard deviations of reactive aggression, proactive aggression, delinquency, and peer delinquency

\begin{tabular}{|c|c|c|c|c|c|c|c|c|c|c|c|c|}
\hline \multirow[b]{2}{*}{ Wave } & \multicolumn{3}{|c|}{ Reactive aggression } & \multicolumn{3}{|c|}{ Proactive aggression } & \multicolumn{3}{|c|}{ Delinquency } & \multicolumn{3}{|c|}{ Peer Delinquency } \\
\hline & $M$ & $S D$ & Range & $M$ & $S D$ & Range & $M$ & $S D$ & Range & $M$ & $S D$ & Range \\
\hline 1 & 16.502 & 7.829 & $8-42$ & 11.419 & 5.483 & $8-43$ & 1.605 & 2.412 & $0-18$ & 6.880 & 1.247 & $6-13$ \\
\hline 2 & 14.460 & 7.252 & $8-44$ & 10.655 & 4.559 & $8-34$ & 1.105 & 2.282 & $0-20$ & 6.789 & 1.437 & $6-14$ \\
\hline 3 & 14.349 & 7.138 & $8-41$ & 10.672 & 4.690 & $8-34$ & 1.384 & 2.558 & $0-16$ & 7.046 & 1.755 & $6-17$ \\
\hline 4 & 14.410 & 7.497 & $8-43$ & 11.116 & 5.192 & $8-37$ & 1.243 & 2.697 & $0-30$ & 7.016 & 1.648 & $6-18$ \\
\hline 5 & 14.430 & 7.830 & $8-55$ & 11.254 & 5.719 & $8-50$ & 0.927 & 1.799 & $0-12$ & 6.945 & 1.582 & $6-15$ \\
\hline 6 & 13.838 & 7.245 & $8-48$ & 10.734 & 5.023 & $8-40$ & 0.780 & 2.298 & $0-25$ & 6.939 & 1.659 & $6-13$ \\
\hline
\end{tabular}

Table 3 Correlations among reactive aggression, proactive aggression, delinquency across the six annual waves and mean peer delinquency

\begin{tabular}{|c|c|c|c|c|c|c|c|c|c|c|c|c|c|c|c|c|c|c|c|}
\hline & 1 & 2 & 3 & 4 & 5 & 6 & 7 & 8 & 9 & 10 & 11 & 12 & 13 & 14 & 15 & 16 & 17 & 18 & 19 \\
\hline 1.Reactive aggression $\mathrm{W} 1$ & - & & & & & & & & & & & & & & & & & & \\
\hline 2.Reactive aggression W2 & .543 & - & & & & & & & & & & & & & & & & & \\
\hline 3.Reactive aggression $\mathrm{W} 3$ & .411 & .542 & - & & & & & & & & & & & & & & & & \\
\hline 4.Reactive aggression $\mathrm{W} 4$ & .372 & .494 & .770 & - & & & & & & & & & & & & & & & \\
\hline 5.Reactive aggression W5 & .365 & .497 & .665 & .628 & - & & & & & & & & & & & & & & \\
\hline 6.Reactive aggression W6 & .332 & .396 & .556 & .597 & .651 & - & & & & & & & & & & & & & \\
\hline 7.Proactive aggression $\mathrm{W} 1$ & .727 & .466 & .295 & .261 & .261 & .194 & - & & & & & & & & & & & & \\
\hline 8.Proactive aggression W2 & .411 & .769 & .464 & .402 & .409 & .314 & .464 & - & & & & & & & & & & & \\
\hline 9.Proactive aggression $\mathrm{W} 3$ & .330 & .463 & .755 & .606 & .544 & .456 & .372 & .558 & - & & & & & & & & & & \\
\hline 10.Proactive aggression $\mathrm{W} 4$ & .338 & .398 & .632 & .749 & .493 & .457 & .338 & .468 & .745 & - & & & & & & & & & \\
\hline 11.Proactive aggression W5 & .278 & .420 & .517 & .444 & .789 & .468 & .270 & .417 & .602 & .538 & - & & & & & & & & \\
\hline 12.Proactive aggression W6 & .254 & .311 & .488 & .471 & .505 & .773 & .241 & .338 & .540 & .533 & .495 & - & & & & & & & \\
\hline 13.Delinquency W1 & .516 & .426 & .289 & .259 & .293 & .213 & .408 & .393 & .316 & .254 & .311 & .160 & - & & & & & & \\
\hline 14.Delinquency W2 & .296 & .494 & .378 & .323 & .398 & .244 & .293 & .518 & .400 & .315 & .347 & .188 & .579 & - & & & & & \\
\hline 15.Delinquency W3 & .319 & .266 & .479 & .369 & .272 & .305 & .310 & .325 & .460 & .384 & .232 & .233 & .360 & .538 & - & & & & \\
\hline 16.Delinquency W4 & .225 & .220 & .355 & .292 & .269 & .317 & .124 & .218 & .331 & .363 & .244 & .278 & .241 & .344 & .585 & - & & & \\
\hline 17.Delinquency W5 & .258 & .284 & .461 & .413 & .413 & .430 & .182 & .231 & .418 & .356 & .361 & .343 & .373 & .392 & .516 & .499 & - & & \\
\hline 18.Delinquency W6 & .215 & .130 & .173 & .197 & .236 & .291 & .159 & .121 & .221 & .248 & .222 & .183 & .348 & .300 & .366 & .437 & .483 & - & \\
\hline 19. Peer delinquency & .352 & .373 & .443 & .372 & .338 & .358 & .245 & .333 & .390 & .376 & .297 & .284 & .445 & .557 & .620 & .608 & .568 & .489 & - \\
\hline
\end{tabular}

Note: $\mathrm{W}=$ annual wave of assessment

All correlations are significant at $p<.05$

significant, the quadratic slope was fixed in the combined two-part model. The model fit of the variety of delinquent acts (part 2) was assessed with a linear and a quadratic growth factor. The addition of the quadratic slope significantly improved the model fit. Thus, the combined unconditional two-part latent growth model included linear and quadratic growth factors for part 1 and part 2. Due to the insignificant variance of the quadratic slope of part 2 , this slope was also constrained to zero to achieve convergence of the model. The continuous part of this model was used in the genetic analyses, because a dichotomous variable is not an indicator of variety of delinquent behavior. In contrast, the continuous variable of delinquency represents the number of different delinquent acts.

Second, the main genetic effect of OXTR and the geneenvironment interaction of $O X T R$ with perceived deviant peer affiliation were examined on the intercepts and slopes of reactive aggression, proactive aggression, and delinquency. Gender was added as a control variable due to its potential influence on the genetic effects based on the mixed findings of previous research in $O X T R$, as well as socioeconomic status (SES) and risk status ( $T$ score $\geq 60$ on the Teacher's Report Form at age 11), which are known predictors of aggression and delinquency (Loeber and Farrington 2000; Murray and Farrington 2010). Gene-based tests that evaluate the joint association of multiple loci in the gene were performed; in this case the combined effect of the five included single nucleotide polymorphisms. The main genetic effect as well as the gene-environment interaction were tested with similarity regressions that evaluated the association between similarities in reactive aggression, proactive aggression, delinquency for pairs of unrelated 
individuals with their genetic similarities in OXTR (Tzeng et al. 2011). The genetic similarity is calculated by the average of the weighted allele matching score between two subjects across the markers (in this case, the 5 included single nucleotide polymorphisms). This method combines marker information through a sum of genotype similarity across markers rather than a sum of genotypes, which avoids canceling opposite effects. The tests were conducted in R using the SIMreg package 1.31 (Tzeng et al. 2011). Given the number of tests performed to include both the initial level and the change over time of the three dependent variables, correction for multiple testing with the False Discovery Rate (FDR) correction at .05 level was applied (Benjamini and Hochberg 1995).

\section{Results}

\section{Descriptive Statistics}

Table 2 presents the means, standard deviations, and range for reactive aggression, proactive aggression, delinquency, and perceived deviant peer affiliation for each annual wave in the total sample. The percentages of participants' engagement in at least one delinquent act across the six waves are as follows: Wave 1: 60.4\%, Wave 2: 44.6\%, Wave $3: 47.1 \%$, Wave $4: 45.2 \%$, Wave $5: 40.6 \%$, and Wave 6: $30.3 \%$. A mean score of perceived deviant peer affiliation across the six waves was computed and used for the geneenvironment interactions $(M=6.895, S D=1.092)$. Table 3 depicts the correlations among the study variables. All the variables were significantly correlated with each other across the six waves.

\section{Developmental Trajectories of Antisocial Behavior}

Tables 4 and 5 present the model fit indices, the means, and the variances for all the latent growth models. The model fit indices showed that quadratic curves were fitted best to the trajectories of reactive and proactive aggression. The model for reactive aggression yielded a significant negative mean

Table 4 Model fit indices for latent growth curve models for proactive aggression, reactive aggression, and delinquency

\begin{tabular}{lllllll}
\hline & \multicolumn{7}{l}{ Model fit indices } \\
\cline { 2 - 7 } & $\chi^{2}$ & df & RMSEA & CFI & TLI & SRMR \\
\hline Reactive aggression & 30.727 & 12 & 0.070 & 0.960 & 0.950 & 0.042 \\
Proactive aggression & 15.789 & 12 & 0.031 & 0.985 & 0.981 & 0.051 \\
Delinquency & 33.997 & 15 & 0.043 & 0.954 & 0.943 & 0.065 \\
\hline
\end{tabular}

RMSEA root mean square error of approximation, $C F I$ comparative fit index, TLI Tucker-Lewis fit index, SRMR standardized root mean square residual of the linear slope, suggesting an overall decrease of reactive aggression from early to late adolescence. The model for proactive aggression showed that the linear and quadratic slopes were not significant, suggesting a fairly stable trajectory of proactive aggression across adolescence. The variances of the intercept, the linear slope, and the quadratic slope were all significant, revealing the presence of individual differences in the initial level and the growth patterns of reactive and proactive aggression in adolescence. From the two-part model of delinquency, the continuous part for the analyses was used. The slopes of the amount of delinquency were not significant, indicative of a stable pattern of delinquency among adolescents who engaged in delinquent behavior. The variances of the intercept and the slope were significant, suggesting that the initial amount of delinquency and the change over time varied among the participants.

Finally, perceived deviant peer affiliation was added to the models to examine its main effect on antisocial behavior controlling for gender, risk status, and SES. Perceived deviant peer affiliation was a significant and positive predictor of the initial level of reactive aggression, proactive aggression, and delinquency (reactive aggression: $2.323, p$ $<.001$; proactive aggression: $0.953, p=.004$; delinquency: $0.222, p<.001)$. The effect of perceived deviant peer affiliation on the slopes was not significant for reactive aggression and proactive aggression, but it was significant for the linear slope of delinquency (linear slope $=0.114, p$ $=.018$; quadratic slope $=-0.017, p=.061)$. This indicated that perceived deviant peer affiliation was associated with the change of delinquency over the course of adolescence.

\section{Main Genetic Effects and Gene x Environment Interaction}

Six gene-based tests were performed to examine the main genetic effect and the interaction effects of OXTR and perceived deviant peer affiliation in the intercepts and quadratic slopes of reactive aggression, proactive aggression, and delinquency. There was no main genetic effect of $O X T R$ on any of the intercepts or slopes of antisocial behavior (see Table 6). However, there were significant gene-environment interactions in the intercepts, but not the slopes, of reactive aggression, proactive aggression, and delinquency. The gene-environment interaction remained significant for proactive aggression (corrected $p=0.047$ ) and delinquency (corrected $p=0.005$ ), but marginal for reactive aggression (corrected $p=0.065$ ) after correction for multiple testing. The findings indicated that $O X T R$ interacted with perceived deviant peer affiliation on the level of proactive aggression and delinquency, but not on the pattern of change over time. To clarify that this effect was indeed a gene-environment interaction effect and not a 
Table 5 Results of the unconditional latent growth curve models for proactive aggression, reactive aggression, and delinquency

\begin{tabular}{|c|c|c|c|c|c|c|}
\hline & \multicolumn{2}{|l|}{ Intercept } & \multicolumn{2}{|c|}{ Linear slope } & \multicolumn{2}{|c|}{ Quadratic slope } \\
\hline & $M$ & Variance & $M$ & Variance & $M$ & Variance \\
\hline Reactive aggression & $16.096 * * *$ & $39.181 * * *$ & $-0.940 * *$ & $16.220 * * *$ & 0.102 & $0.485 * * *$ \\
\hline Proactive aggression & $11.045 * * *$ & $13.283 * * *$ & -0.128 & $6.448 * *$ & 0.020 & $0.175^{*}$ \\
\hline Delinquency & $0.535 * * *$ & $0.262 * * *$ & -0.039 & $0.013 *$ & -0.015 & 0 \\
\hline
\end{tabular}

Note: $* p<.05 . * * p<.01 . * * * p<.001$
Table 6 Results of the gene-based tests for proactive aggression, reactive aggression, and delinquency

\begin{tabular}{lllll}
\hline & T.G. & $p$ & T.GxE & $p$ \\
\hline Reactive aggression-intercept & 0.783 & .908 & 7.171 & .032 \\
Reactive aggression-slope & 283.406 & .278 & 214.765 & .385 \\
Proactive aggression-intercept & 9.49 & .339 & 27.807 & .016 \\
Proactive aggression-slope & 221.431 & .914 & 1.564 & .084 \\
Delinquency-intercept & 410.235 & .657 & 3643.994 & .0008 \\
Delinquency-slope & 1764.687 & .999 & 23100.637 & .089 \\
\hline
\end{tabular}

Note: $\mathrm{T} . \mathrm{G}=$ main genetic effect, $\mathrm{T} . \mathrm{GxE}=$ interaction effect

masked gene-environment correlation, a test for geneenvironment correlation between OXTR and perceived deviant peer affiliation was conducted controlling for gender, risk status, and SES. The results showed that OXTR was not significantly correlated with perceived deviant peer affiliation (T.G. $=81.679, p=.194)$.

The sample size, attrition rates, reasons for exclusion, and computation of measured variables were reported in the Method section and used as such in the reported analyses and results without any other manipulations.

\section{Discussion}

Gene-environment interactions in antisocial behavior have gained interest and revealed that several genes interact with environmental factors, such as perceived deviant peer affiliation, in the development of antisocial behavior. However, there is one gene that although it has been associated with both prosocial and antisocial behaviors (Bakermans-Kranenburg and Van IJzendoorn 2013; Ebstein et al. 2012; Lee et al. 2009), it has not been investigated in gene-environment interaction studies yet; the OXTR gene. OXTR is involved in the development of the social brain (Vaidyanathan and Hammock 2016) and it might affect the formation of social relationships in adolescence, especially peer relations. Given its complex involvement not only in prosocial and antisocial behavior, but also in social affiliation, it seems essential to investigate its interaction with deviant peer affiliation and not only its direct effect on antisocial behavior. The present study aimed to examine whether OXTR interacts with perceived deviant peer affiliation in antisocial behavior in adolescents aged from 13 to 18 , using a longitudinal design and gene-based testing. Importantly, three components of antisocial behavior were examined, reactive aggression, proactive aggression, and delinquency to capture the complexity of antisocial behavior. The findings revealed no main direct effect of OXTR in antisocial behavior, but a significant gene-environment interaction between OXTR polymorphisms and perceived deviant peer affiliation in proactive aggression and delinquency.

More specifically, there was no main genetic effect of OXTR polymorphisms on antisocial behavior, but there was a main effect of perceived deviant peer affiliation on all dependent variables. The role of perceived deviant peer affiliation in antisocial behavior has been well established in previous research (Dishion et al. 1995; Vitaro et al. 2015), but the findings on main effects of OXTR are inconsistent. Previous research examined various single nucleotide polymorphisms of the OXTR in relation to antisocial behavior using SNP-based tests and although some studies found significant effects of a limited number of single nucleotide polymorphisms (Hovey et al. 2015; LoParo et al. 2016; Malik et al. 2012; Smearman et al. 2015), others did not find effects that survived correction for multiple testing (Malik et al. 2014; Sakai et al. 2012). In this study, genebased tests were used to overcome the limitations of SNPbased tests, as they include a number of single nucleotide polymorphisms in one test, increasing the detectability of associations by aggregating small effects and reducing the number of tests (Tzeng et al. 2011). The findings suggest that OXTR does not have a direct effect on any aspect of antisocial behavior but it rather interacts with perceived deviant peer affiliation. However, it is important to highlight that only five single nucleotide polymorphisms were included that did not provide coverage of the entire OXTR gene. Speculatively, the addition of more single nucleotide polymorphisms in future gene-based tests might reveal a potential small direct effect of OXTR. In addition, the sample size was small and did not have the power to detect small direct effects. Considering the role of OXTR in social behavior and affiliation, the gene-environment interaction of OXTR with perceived deviant peer affiliation can provide 
more useful information on how the undeniable role of peers in adolescent antisocial behavior might also be related to the genetic makeup.

This interaction suggests that the effect of perceived deviant peer affiliation on antisocial behavior might be influenced by $O X T R$ variations. Given that gene-based tests are not direction tests, it is not possible to reveal specific risk alleles, as each single nucleotide polymorphism has its own positive or negative loading (see also LoParo et al. 2016 for a similar methodology). Considering the role of oxytocin in a broad spectrum of social behaviors, such as social affiliation, pair bonding, and trust (MacDonald and MacDonald 2010) as well as OXTR's role in the development of the social brain (Vaidyanathan and Hammock 2016), it is possible that variations in OXTR have a differential effect on the regulation of oxytocin that consequently leads to different interaction effects with peers.

For instance, adolescents with specific OXTR variations might be more prone to behave similarly to their peers in an effort to seek acceptance and bonding and thus exhibit the same behavior as their peers (positive or negative), supporting the differential susceptibility model. There is evidence indicating that oxytocin administration can enhance trust toward individuals who are seen as trustworthy or belong to the "in-group", but can have the opposite effect for the "out-group" or toward individuals who are seen as untrustworthy (Bartz et al. 2010, 2011; Van IJzendoorn and Bakermans-Kranenburg 2012). In addition, it has been suggested that oxytocin might be related to self-referential processing and interoception that may promote in-group survival (Hurlemann and Scheele 2016). This raises the question whether $O X T R$ function might play a role in how adolescents perceive and affiliate with their peers compared to the "rest of the world". They might trust their in-group of peers and exhibit matching behaviors. They potentially perceive as untrustworthy those who are considered to be outside of their in-group circle and simultaneously exhibit aggressive behavior toward them. This potential explanation, however, is based on previous studies on oxytocin administration and not on genetic variations of $O X T R$. A further and closer investigation of this gene-environment interaction could shed additional light on how $O X T R$ affects the formation of peer relationships, in-group and out-group trust, as well as the paths toward antisocial behavior.

In addition, this gene-environment interaction might be driven by the link between oxytocin and prosocial behavior. Transient $O X T R$ expression during neocortical development might increase neural activity in response to multisensory inputs and shape the processing of social inputs (Vaidyanathan and Hammock 2016). A specific brain activation network has been identified in empathy, consisting of the anterior midcingulate cortex (aMCC), the dorsal anterior cingulate cortex (dACC), the dorsal-caudal edge extending to supplementary motor area (SMA), and bilateral anterior insula (Fan et al. 2011). Moreover, it has been suggested that the development of empathy emerges very early in life and can be detected in neurophysiological patterns in infancy (Tousignant et al. 2017), a period with increased OXTR expression in the neocortex. Previous genetic studies have also shown that $O X T R$ variations are associated with empathy (Rodrigues et al. 2009; Uzefovsky et al. 2015) and oxytocin administration enhances empathy and emotion recognition especially in individuals with social-affective deficits (Bartz et al. 2011).

It is hence possible that $O X T R$ variations might be related to impairments in empathy and prosocial behavior that could relate to the development of antisocial behavior. Speculatively, this effect might interact with the social environment and lead to the development of antisocial behavior only when adolescents affiliate with deviant peers, supporting the diathesis-stress model. Alternatively, the differential susceptibility model might also be in place. Positive peer affiliation might be beneficial for the development of empathy and prosocial behavior, especially in youth with social deficits, whereas deviant peer affiliation might reinforce these deficits and lead to antisocial behavior. Overall, there are several interesting approaches to interpret this gene-environment interaction, but they merit further exploration to draw solid conclusions. It would be especially beneficial to examine this gene-environment interaction not only in relation to perceived deviant peer affiliation but also in relation to positive and supportive peer groups to decipher whether this interaction supports the diathesis-stress model or the differential susceptibility model.

It is important to mention that the results remained significant for proactive aggression but not for reactive aggression after correction for multiple testing. These two types of aggression have distinct characteristics and are related to different processes and outcomes (Hubbard et al. 2010). A recent study found a gene-environment interaction between Monoamine Oxidase A (MAOA) and Catechol-OMethyltransferase (COMT) genes and parenting on reactive aggression but not on proactive aggression, highlighting the differential genetic contribution of these two types of aggression (Zhang et al. 2016). In the present study, OXTR interacted with deviant peers on proactive aggression but not on reactive aggression, suggesting that this interaction might be specific to proactive aggression. However, the corrected alpha level was .06 for reactive aggression, which advise us to interpret this finding with caution. It is possible that this result would remain significant in a larger study and hence it seems imperative to replicate it in larger studies before drawing solid conclusions.

Moreover, the gene-environment interaction did not predict how antisocial behavior changed over time. 
Previous research yielded different trajectories of antisocial behavior over the course of adolescence that usually included multiple classes (Reef et al. 2011; Van Lier et al. 2007). The present sample size was not large enough for a latent class analysis and it is possible that the geneenvironment interaction might be significant for specific classes but not for the total sample. Using the overall change over time, it is not possible to detect a specific effect of the interaction in a particular class. Larger studies are highly needed to unravel whether this gene-environment interaction affects a specific class of antisocial behavior. Importantly, the gene-environment interaction on the intercept indicates that $O X T R$ variations interact with perceived deviant peer affiliation in early adolescence (age 13). It has been posited that childhood-onset antisocial behavior is more severe, has more adverse outcomes, and is more biologically driven compared to adolescent-onset antisocial behavior (Moffitt et al. 1996). In line with this theory, it is possible that genetic contributions and interactions with perceived deviant peer affiliation are more relevant in antisocial behavior at an early age and might be indicative of more severe antisocial behavior.

In addition, a study suggested that the effect of deviant peer affiliation, although substantial, it might have been overestimated in previous studies and the effects of social control processes might have been underestimated (Haynie and Osgood 2005). The authors found that the effects of peer delinquency and unstructured socializing on delinquency were comparable. Taking into account the development of self-regulation and inhibitory control from childhood to adolescence (Steinberg 2008), the role of psychosocial immaturity in persistent antisocial behavior (Monahan et al. 2013) as well as the genetic contribution to inhibitory control (Weafer et al. 2017), it is reasonable to assume that younger adolescents might be more prone to gene-environment interactions with peers compared to older adolescents especially in unstructured settings. It would be interesting for future research to explore this geneenvironment interaction in younger children and also incorporate other social control contexts to better understand the developmental process of this interaction.

Finally, the developmental trajectories of antisocial behavior showed that reactive aggression decreased over time, whereas proactive aggression and delinquency remained stable. Previous research has identified multiple classes in aggression and delinquency, suggesting the presence of stable low or moderate levels, increasing levels, or stable high levels of antisocial behavior in adolescence (Landsheer and van Dijkum 2005; Reef et al. 2011). Specifically, for reactive and proactive aggression, a study found that in proactive aggression, the majority of adolescents exhibited a low stable trajectory, followed by adolescents with moderate stable and high peaking proactive aggression (Barker et al. 2010). In reactive aggression, the majority of adolescents exhibited a moderate desisting pattern, followed by low stable and high peaking patterns. In addition, proactive aggression is related to and predictive of delinquency in adolescence and they seem to follow similar trajectories (Hubbard et al. 2010).

It has been suggested that reactive aggression, but not proactive aggression is highly associated with peer rejection and victimization (Hubbard et al. 2010). As adolescents grow older, they develop more efficient coping strategies and peer victimization and physical fighting decrease as they learn to use these coping strategies in conflict resolution (Compas et al. 2017; Rudatsikira et al. 2008; ZimmerGembeck and Skinner 2016). It is thus possible that the decrease of reactive aggression might be explained by the development of coping strategies in late adolescence that have been related to lower levels of psychopathology (Compas et al. 2017). In contrast, proactive aggression, especially at a young age, is related to callous-unemotional traits and psychopathy in adulthood, more adverse outcomes in the long run, and higher levels of antisocial behavior and delinquency (Frick et al. 2014). Importantly, the stability of proactive aggression over time is more strongly explained by genetic factors than the stability of reactive aggression (Tuvblad and Baker 2011). Overall, the findings are in line with previous studies on developmental trajectories of antisocial behavior, although specific classes were not examined as they were out of the scope of this study.

Several limitations of this study should also be mentioned to better understand the generalizability of the findings and suggest useful directions for future research. First, a community sample of adolescents who were at risk of externalizing problems were recruited but they were not clinical patients and the sample size was small. Genetic studies using larger samples and clinical populations are necessary to confirm the present findings and examine whether this interaction is different in clinical populations. Second, this study did not have the power to examine gender differences that have been found in previous research with SNP-based tests. Speculatively, this geneenvironment interaction may be more pronounced in males given the stronger evidence of a direct effect of OXTR in antisocial behavior as well as the higher rates of antisocial behavior and deviant peer affiliation in boys and male adults. Relatedly, the sample lacked the power to examine classes of trajectories that might be specifically related to the gene-environment interaction under investigation. Third, although gene-based tests that are advantageous compared to SNP-based tests were used, a small number of single nucleotide polymorphisms was included in this study. The inclusion of five single nucleotide 
polymorphisms was based on their associations with social and antisocial behavior in previous research as well as their role in the expression of the gene as a meaningful and economical first step toward exploring this geneenvironment interaction. The inclusion of a large number of single nucleotide polymorphisms in future gene-based tests is highly recommended, as it would provide a more robust measurement of the OXTR gene. Fourth, this study recruited a sample of adolescents aged 13 to 18 , but it would be very elucidating for future studies to explore different developmental trajectories from an earlier age. Fifth, an indirect measurement of deviant peer affiliation was used in this study, which is not the optimal methodology. It has been proposed that indirect measurements of peer delinquency suffer from several shortcomings (Young et al. 2015), which should be taken into account when interpreting the findings of this study. The measurement used in this study has been examined in comparison to direct measures of peer delinquency and the authors concluded that indirect measures were reliable but might underreport peer delinquency, potentially because responders might not be aware of all the delinquent acts committed by their friends (Weerman and Smeenk 2005). Sixth, this study was focused on perceived deviant peer affiliation, but this is only one aspect of peer affiliation. Future studies should also investigate potential gene-environment interactions with perceived peer support and more positive peer groups. Last but not least, given the role of OXTR in social and prosocial behavior, it is essential for future research to examine more potential gene-environment interactions of OXTR with other socially relevant environmental factors that could be involved in antisocial behavior, such as family relations or parental style.

\section{Conclusion}

The aim of this study was to contribute to the genetic research of antisocial behavior by examining the geneenvironment interaction of $O X T R$ and perceived deviant peer affiliation in antisocial behavior. OXTR has been associated with both social affiliation and antisocial behavior but its interaction with deviant peer affiliation, which is a strong predictor of antisocial behavior in youth and a fundamental expression of social relationships, has been overlooked so far. This longitudinal study provided evidence of a gene-environment interaction of OXTR and perceived deviant peer affiliation on antisocial behavior using gene-based tests, but found no main genetic effect of OXTR polymorphisms. The findings underscore that genetic variation in the OXTR might affect the influence of deviant peer affiliation on antisocial behavior, contributing to a better understanding of individual differences in antisocial behavior during adolescence. Taken together, this study suggests that addressing potential gene-environment interactions of $O X T R$ and perceived deviant peer affiliation as well as other socially relevant environmental factors in antisocial behavior in larger clinical studies might be a promising direction to disentangle its neurobiology.

Authors' Contributions I.F. conceived of the study, performed the statistical analyses and interpreted the data, and drafted the manuscript. M.C. conceived of the study, participated in the interpretation of the data, and helped to draft the manuscript. M.V. conceived of the study, participated in the interpretation of the data, and helped to draft the manuscript. D.M. participated in the design and coordination of the RADAR-y project, helped to perform the statistical analyses and to draft the manuscript. M.B. participated in the design of the RADAR-y project, helped to perform the statistical analyses and to draft the manuscript. P.L. participated in the design and coordination of the RADAR-y project and helped to draft the manuscript. H.K. participated in the design and coordination of the RADAR-y project and helped to draft the manuscript. S.B. participated in the design and coordination of the RADAR-y project and helped to draft the manuscript. W.M. participated in the design and coordination of the RADAR-y project and helped to draft the manuscript. All authors read and approved the final manuscript.

Funding The RADAR-y project has been financially supported by grants from the Netherlands Organisation for Scientific Research (GBMAGW 480-03-005,GB-MAGW 480-08-006), the Stichting Achmea Slachtoffer en Samenleving (SASS), a grant from the Netherlands Organisation for Scientific Research to the Consortium Individual Development (CID; 024.001.003), and several other grants from the Netherlands Organisation for Scientific Research, VU University Amsterdam, and Utrecht University.

Data Sharing and Declaration The datasets generated and/or analyzed during the current study are not publicly available but are available from the corresponding author on reasonable request.

\section{Compliance with Ethical Standards}

Conflict of Interest The authors declare that they have no conflict of interest.

Ethical Approval The study has been granted Medical Ethical approval from the University Medical Center Utrecht. All procedures performed in studies involving human participants were in accordance with the ethical standards of the institutional and/or national research committee and with the 1964 Helsinki declaration and its later amendments or comparable ethical standards.

Informed Consent Informed consent was obtained from all individual participants and their legal representatives included in the study.

Open Access This article is distributed under the terms of the Creative Commons Attribution 4.0 International License (http://crea tivecommons.org/licenses/by/4.0/), which permits use, duplication, adaptation, distribution, and reproduction in any medium or format, as long as you give appropriate credit to the original author(s) and the source, provide a link to the Creative Commons license, and indicate if changes were made. 


\section{References}

Achenbach, T. M. (1991). Manual for the Youth Self report and 1991 profiles. Burlington: Department of Psychiatry, University of Vermont.

Assink, M., van der Put, C. E., Hoeve, M., de Vries, S. L. A., Stams, G. J. J. M., \& Oort, F. J. (2015). Risk factors for persistent delinquent behavior among juveniles: A meta-analytic review. Clinical Psychology Review, 42, 47-61.

Bakermans-Kranenburg, M., \& Van IJzendoorn, M. (2013). Sniffing around oxytocin: review and meta-analyses of trials in healthy and clinical groups with implications for pharmacotherapy. Translational Psychiatry, 3(5), e258.

Barker, E. D., Vitaro, F., Lacourse, E., Fontaine, N. M. G., Carbonneau, R., \& Tremblay, R. E. (2010). Testing the developmental distinctiveness of male proactive and reactive aggression with a nested longitudinal experimental intervention. Aggressive Behavior, 36, $127-140$.

Barrett, J. C., Fry, B., Maller, J., \& Daly, M. J. (2005). Haploview: Analysis and visualization of LD and haplotype maps. Bioinformatics, 21(2), 263-265.

Bartz, J. A., Zaki, J., Bolger, N., Hollander, E., Ludwig, N. N., \& Kolevzon, A., et al. (2010). Oxytocin selectively improves empathic accuracy. Psychological Science, 21(10), 1426-1428.

Bartz, J. A., Zaki, J., Bolger, N., \& Ochsner, K. N. (2011). Social effects of oxytocin in humans: context and person matter. Trends in Cognitive Sciences, 15(7), 301-309.

Belsky, J., \& Pluess, M. (2009). Beyond diathesis stress: Differential susceptibility to environmental influences. Psychological Bulletin, 135(6), 885-908.

Bendixen, M., Endresen, I. M., \& Olweus, D. (2003). Variety and frequency scales of antisocial involvement: Which one is better? Legal and Criminological Psychology, 8(2), 135-150.

Benjamini, Y., \& Hochberg, Y. (1995). Controlling the false discovery rate: A practical and powerful approach to multiple testing. Journal of the Royal Statistical Society, Series B (Methodological), 57(1), 289-300.

Bezdjian, S., Tuvblad, C., Raine, A., \& Baker, L. A. (2011). The genetic and environmental covariation among psychopathic personality traits, and reactive and proactive aggression in childhood. Child Development, 82(4), 1267-1281.

Browne, M. W., Cudeck, R., Bollen, K. A., \& Long, J. S. (1993). Alternative ways of assessing model fit. Sage Focus Editions, 154, 136-136.

Cima, M., \& Raine, A. (2009). Distinct characteristics of psychopathy relate to different subtypes of aggression. Personality and Individual Differences, 47(8), 835-840.

Compas, B. E., Jaser, S. S., Bettis, A. H., Watson, K. H., Gruhn, M. A., Dunbar, J. P., \& Thigpen, J. C. (2017). Coping, emotion regulation, and psychopathology in childhood and adolescence: a meta-analysis and narrative review. Psychological Bulletin, 143 (9), 939-991.

Connolly, E. J., Schwartz, J. A., Nedelec, J. L., Beaver, K. M., \& Barnes, J. (2015). Different slopes for different folks: Genetic influences on growth in delinquent peer association and delinquency during adolescence. Journal of Youth and Adolescence, 44(7), 1413-1427.

Delaneau, O., Zagury, J.-F., \& Marchini, J. (2013). Improved wholechromosome phasing for disease and population genetic studies. Nature Methods, 10(1), 5-6.

Dishion, T. J., French, D. C., \& Patterson, G. R. (1995). The development and ecology of antisocial behavior. In D. Cicchetti \& D. J. Cohen (Eds.), Developmental Psychopathology. Second Edition, Hoboken, NJ: John Wiley \& Sons Inc.
Ebstein, R. P., Knafo, A., Mankuta, D., Chew, S. H., \& San Lai, P. (2012). The contributions of oxytocin and vasopressin pathway genes to human behavior. Hormones and Behavior, 61(3), 359379.

Erskine, H. E., Norman, R. E., Ferrari, A. J., Chan, G. C. K., Copeland, W. E., Whiteford, H. A., \& Scott, J. G. (2016). Long-Term Outcomes of Attention-Deficit/Hyperactivity Disorder and Conduct Disorder: A Systematic Review and Meta-Analysis. Journal of the American Academy of Child and Adolescent Psychiatry, 55 (10), 841-50.

Fan, Y., Duncan, N. W., de Greck, M., \& Northoff, G. (2011). Is there a core neural network in empathy? An fMRI based quantitative meta-analysis. Neuroscience and Biobehavioral Reviews, 35, 903-911.

Ferguson, C. J. (2010). Genetic contributions to antisocial personality and behavior: A meta-analytic review from an evolutionary perspective. The Journal of Social Psychology, 150(2), 160-180.

Fragkaki, I., Cima, M., \& Granic, I. (2017). The role of trauma in the hormonal interplay of cortisol, testosterone, and oxytocin in adolescent aggression. Psychoneuroendocrinology, 88, 24-37.

Frick, P. J., Ray, J. V., Thornton, L. C., \& Kahn, R. E. (2014). Can callous-unemotional traits enhance the understanding, diagnosis, and treatment of serious conduct problems in children and adolescents? A comprehensive review. Psychological Bulletin, 140 (1), 1-57.

Gimpl, G., \& Fahrenholz, F. (2001). The oxytocin receptor system: Structure, function, and regulation. Physiological Reviews, 81(2), 629-683.

Guastella, A. J., \& MacLeod, C. (2012). A critical review of the influence of oxytocin nasal spray on social cognition in humans: Evidence and future directions. Hormones and Behavior, 61(3), $410-418$

Hacker, K., Arsenault, L., Franco, I., Shaligram, D., Sidor, M., Olfson, M., \& Goldstein, J. (2014). Referral and follow-up after mental health screening in commercially insured adolescents. Journal of Adolescent Health, 55, 17-23.

Haynie, D. L., \& Osgood, D. W. (2005). Reconsidering peers and delinquency: How do peers matter? Social Forces, 84(2), 11091130.

Hovey, D., Lindstedt, M., Zettergren, A., Jonsson, L., Johansson, A., \& Melke, J., et al. (2015). Antisocial behavior and polymorphisms in the oxytocin receptor gene: findings in two independent samples. Molecular Psychiatry, 21(7), 983-988.

Hu, L. T., \& Bentler, P. M. (1999). Cutoff criteria for fit indexes in covariance structure analysis: Conventional criteria versus new alternatives. Structural Equation Modeling: A Multidisciplinary Journal, 6(1), 1-55.

Hubbard, J. A., McAuliffe, M. D., Morrow, M. T., \& Romano, L. J. (2010). Reactive and proactive aggression in childhood and adolescence: Precursors, outcomes, processes, experiences, and measurement. Journal of Personality, 78(1), 95-118.

Hung, L. W., Neuner, S., Polepalli, J. S., Wright, M., Walsh, J. J., Lewis, E. M., \& Malenka, R. C. (2017). Gating of social reward by oxytocin in the ventral tegmental area. Science, 357(6358), 1406-1411.

Hurlemann, R., \& Scheele, D. (2016). Dissecting the role of oxytocin in the formation and loss of social relationships. Biological Psychiatry, 79, 185-193.

Junger-Tas, J., \& Marshall, I. H. (1999). The self-report methodology in crime research. Crime and Justice, 25, 291-367.

Junger-Tas, J., Terlouw, G.-J., \& Klein, M. W. (1994). Delinquent behavior among young people in the western world: First results of the international self-report delinquency study. Amsterdam/ New York: Kugler Publications. 
Keijsers, L., Branje, S., Hawk, S. T., Schwartz, S. J., Frijns, T., \& Koot, H. M., et al. (2012). Forbidden friends as forbidden fruit: Parental supervision of friendships, contact with deviant peers, and adolescent delinquency. Child Development, 83(2), 651-666.

Kempes, M., Walter, M., de Vries, H., \& van Engeland, H. (2005). Reactive and proactive aggression in children. A review of theory, findings and the relevance for child and adolescent psychiatry. European Child and Adolescent Psychiatry, 14, 11-19.

Korn, J. M., Kuruvilla, F. G., McCarroll, S. A., Wysoker, A., Nemesh, J., \& Cawley, S., et al. (2008). Integrated genotype calling and association analysis of SNPs, common copy number polymorphisms and rare CNVs. Nature Genetics, 40(10), 1253-1260.

Landsheer, J. A., \& van Dijkum, C. (2005). Male and female delinquency trajectories from pre through middle adolescence and their continuation in late adolescence. Adolescence, 40(160), 729.

Lee, H.-J., Macbeth, A. H., Pagani, J. H., \& Young, W. S. (2009). Oxytocin: the great facilitator of life. Progress in Neurobiology, $88(2), 127-151$.

Lee, P. H., \& Shatkay, H. (2008). F-SNP: computationally predicted functional SNPs for disease association studies. Nucleic Aci Research, 36(suppl 1), D820-D824.

Linder, J. R., Crick, N. R., \& Collins, W. A. (2002). Relational aggression and victimization in young adults' romantic relationships: Associations with perceptions of parent, peer, and romantic relationship quality. Social Development, 11(1), 69-86.

Lobbelstael, J., Cima, M., \& Lemmens, A. (2015). The relationship between personality disorder traits and reactive versus proactive motivation for aggression. Psychiatry Research, 229(1), 155160.

Loeber, R., \& Farrington, D. P. (2000). Young children who commit crime: Epidemiology, developmental origins, risk factors, early interventions, and policy implications. Development and Psychopathology, 12(4), 737-762.

LoParo, D., Johansson, A., Walum, H., Westberg, L., Santtila, P., \& Waldman, I. (2016). Rigorous tests of gene-environment interactions in a lab study of the oxytocin receptor gene (OXTR), alcohol exposure, and aggression. American Journal of Medical Genetics Part B: Neuropsychiatric Genetics, 171(5), 589-602.

MacCallum, R. C., Browne, M. W., \& Sugawara, H. M. (1996). Power analysis and determination of sample size for covariance structure modeling. Psychological Methods, 1(2), 130-149.

MacDonald, K., \& MacDonald, T. M. (2010). The peptide that binds: A systematic review of oxytocin and its prosocial effects in humans. Harvard Review of Psychiatry, 18(1), 1-21.

Maciejewski, D. F., Lier, P. A., Branje, S. J., Meeus, W. H., \& Koot, H. M. (2015). A 5-year longitudinal study on mood variability across adolescence using daily diaries. Child Development, 86(6), 1908-1921.

Malik, A. I., Zai, C. C., Abu, Z., Nowrouzi, B., \& Beitchman, J. H. (2012). The role of oxytocin and oxytocin receptor gene variants in childhood-onset aggression. Genes, Brain and Behavior, 11(5), 545-551.

Malik, A. I., Zai, C. C., Berall, L., Abu, Z., Din, F., \& Nowrouzi, B., et al. (2014). The role of genetic variants in genes regulating the oxytocin-vasopressin neurohumoral system in childhood-onset aggression. Psychiatric Genetics, 24(5), 201-210.

McCarroll, S. A., Kuruvilla, F. G., Korn, J. M., Cawley, S., Nemesh, J., \& Wysoker, A., et al. (2008). Integrated detection and population-genetic analysis of SNPs and copy number variation. Nature Genetics, 40(10), 1166-1174.

Moffitt, T. E., Caspi, A., Dickson, N., Silva, P., \& Stanton, W. (1996). Childhood-onset versus adolescent-onset antisocial conduct problems in males: Natural history from ages 3 to 18 years. Development and Psychopathology, 8(02), 399-424.

Monahan, K. C., Steinberg, L., Cauffman, E., \& Mulvey, E. (2013). Psychosocial (im)maturity from adolescence to early adulthood:
Distinguishing between adolescence-limited and persisting antisocial behavior. Development and Psychopathology, 25, 10931105.

Morales, J., \& Crick, N. (1998). Self-report measure of aggression and victimization. Unpublished measure.

Morizot, J., \& Kazemian, L. (2015). The development of criminal and antisocial behavior Theory, research and practical applications. Switzerland: Springer International Publishing.

Murray, J., \& Farrington, D. P. (2010). Risk factors for conduct disorder and delinquency: Key findings from longitudinal studies. The Canadian Journal of Psychiatry, 55(10), 633-642.

Muthén, L. K., \& Muthén, B. O. (1998). Mplus user's guide. Seventh Edition. Los Angeles,CA: Muthén \& Muthén. 2015.

Ostrov, J. M., \& Houston, R. J. (2008). The utility of forms and functions of aggression in emerging adulthood: Association with personality disorder symptomatology. Journal of Youth and Adolescence, 37, 1147-1158.

Pappa, I., Pourcain, B. S., Benke, K., Cavadino, A., Hakulinen, C., \& Nivard, M. G., et al. (2016). A genome-wide approach to children's aggressive behavior: the EAGLE consortium. American Journal of Medical Genetics Neuropsychiatric Genetics, 171(5), $562-72$.

Purcell, S., Neale, B., Todd-Brown, K., Thomas, L., Ferreira, M. A., \& Bender, D., et al. (2007). PLINK: a tool set for whole-genome association and population-based linkage analyses. The American Journal of Human Genetics, 81(3), 559-575.

Reef, J., Diamantopoulou, S., van Meurs, I., Verhulst, F. C., \& van der Ende, J. (2011). Developmental trajectories of child to adolescent externalizing behavior and adult DSM-IV disorder: Results of a 24-year longitudinal study. Social Psychiatry and Psychiatric Epidemiology, 46(12), 1233-1241.

Rudatsikira, E., Muula, A.S., \& Siziya, S. (2008). Variables associated with physical fighting among US high-school students. Clinical Practice and Epidemiology in Mental Health, 4, 16.

Rodrigues, S. M., Saslow, L. R., Garcia, N., John, O. P., \& Keltner, D. (2009). Oxytocin receptor genetic variation relates to empathy and stress reactivity in humans. PNAS, 106(50), 21437-21441.

Sakai, J. T., Crowley, T. J., Stallings, M. C., McQueen, M., Hewitt, J. K., \& Hopfer, C., et al. (2012). Test of association between 10 single nucleotide polymorphisms in the oxytocin receptor gene and conduct disorder. Psychiatric Genetics, 22(2), 99-102.

Shamay-Tsoory, S. G., \& Abu-Akel, A. (2016). The social salience hypothesis of oxytocin. Biological Psychiatry, 79, 194-202.

Skripkauskaite, S., Hawk, S. T., Branje, S. J. T., Koot, H. M., van Lier, P. A. C., \& Meeus, W. (2015). Reactive and proactive aggression: differential links with emotion regulation difficulties, maternal criticism in adolescence. Aggressive Behavior, 41, 214-226.

Smearman, E. L., Winiarski, D. A., Brennan, P. A., Najman, J., \& Johnson, K. C. (2015). Social stress and the oxytocin receptor gene interact to predict antisocial behavior in an at-risk cohort. Development and Psychopathology, 27(01), 309-318.

Steinberg, L. (2008). A social neuroscience perspective on adolescent risk-taking. Developmental Review, 28, 78-106.

Steinberg, L., \& Morris, A. S. (2001). Adolescent development. Annual Review of Psychology, 52, 83-110.

Tousignant, B., Eugene, F., \& Jackson, P. L. (2017). A developmental perspective on the neural bases of human empathy. Infant Behavior and Development, 48, 5-12.

Tuvblad, C., \& Baker, L. A. (2011). Human aggression across the lifespan: genetic propensities and environmental moderators. Advances in Genetics, 75, 171-214.

Tuvblad, C., Narusyte, J., Grann, M., Sarnecki, J., \& Lichtenstein, P. (2011). The genetic and environmental etiology of antisocial behavior from childhood to emerging adulthood. Behavior Genetics, 41(5), 629-640. 
Tzeng, J. Y., Zhang, D., Pongpanich, M., Smith, C., McCarthy, M. I., \& Sale, M. M., et al. (2011). Studying gene and geneenvironment effects of uncommon and common variants on continuous traits: A marker-set approach using gene-trait similarity regression. The American Journal of Human Genetics, 89 (2), 277-288.

Uzefovsky, F., Shalev, I., Israel, S., Edelman, S., Raz, Y., \& Mankuta, D., et al. (2015). Oxytocin receptor and vasopressin receptor 1a genes are respectively associated with emotional and cognitive empathy. Hormones and Behavior, 67, 60-65.

Vaidyanathan, R., \& Hammock, E. A. D. (2016). Oxytocin receptor dynamics in the brain across development and species. Developmental Neurobiology, 77(2), 143-157.

Van IJzendoorn, M. H., \& Bakermans-Kranenburg, M. J. (2012). A sniff of trust: Meta-analysis of the effects of intranasal oxytocin administration on face recognition, trust to in-group, and trust to out-group. Psychoneuroendocrinology, 37, 438-443.

van Leeuwen, E. M., Kanterakis, A., Deelen, P., Kattenberg, M. V., Slagboom, P. E., \& de Bakker, P. I., et al. (2015). Populationspecific genotype imputations using minimac or IMPUTE2. Nature Protocols, 10(9), 1285-1296.

Van Lier, P. A., Wanner, B., \& Vitaro, F. (2007). Onset of antisocial behavior, affiliation with deviant friends, and childhood maladjustment: A test of the childhood-and adolescent-onset models. Development and Psychopathology, 19(01), 167-185.

Veening, J. G., \& Olivier, B. (2013). Intranasal administration of oxytocin: Behavioral and clinical effects, a review. Neuroscience \& Biobehavioral Reviews, 37(8), 1445-1465.

Vitaro, F., Brendgen, M., \& Lacourse, E. (2015). 14 Peers and Delinquency: A Genetically Informed, Developmentally Sensitive Perspective. In J. Morizot \& L. Kazemian (Eds.), The Development of Criminal and Antisocial Behavior Theory, research and practical applications (pp. 221-236). Switzerland: Springer International Publishing.

Vitaro, F., Brendgen, M., \& Barker, E. D. (2006). Subtypes of aggressive behaviors: A developmental perspective. International Journal of Behavioral Development, 30(1), 12-19.

Waller, R., Corral-Frías, N. S., Vannucci, B., Bogdan, R., Knodt, A. R., \& Hariri, A. R., et al. (2016). An oxytocin receptor polymorphism predicts amygdala reactivity and antisocial behavior in men. Social Cognitive and Affective Neuroscience, 11(8), 12181226.

Weafer, J., Gray, J. C., Hermandez, K., Palmer, A. A., MacKillop, J., $\&$ de Wit, H. (2017). Hierarchical investigation of genetic influences on response inhibition in healthy young adults. Experimental and Clinical Psychopharmacology, 25(6), 512-520.

Weerman, F. M., \& Smeenk, W. H. (2005). Peer similarity in delinquency for different types of friends: A comparison using two measurement methods. Criminology, 43(2), 499-524.

Young, J. T. N., Rebellon, C. J., Barnes, J. C., \& Weerman, F. M. (2015). What do alternative measures of peer behavior tell us? Examining the discriminant validity of multiple methods of measuring peer deviance and the implications for etiological models. Justice Quarterly, 32(4), 626-652.

Zhang, W., Cao, C., Wang, M., Ji, L., \& Cao, Y. (2016). Monoamine oxidase a (MAOA) and catechol-o-methyltransferase (COMT) gene polymorphisms interact with maternal parenting in association with adolescent reactive aggression but not proactive aggression: evidence of differential susceptibility. Journal of Youth and Adolescence, 45(4), 812-829.

Zhao, G., Marceau, R., Zhang, D., \& Tzeng, J.Y. (2015). Assessing Gene-Environment Interactions for Common and Rare Variants with Binary Traits Using Gene-Trait Similarity Regression. Genetics, 199(3), 695-710.

Zimmer-Gembeck, M. J., \& Skinner (2016). The development of coping: implications for psychopathology and resilience. In D.
Cicchetti (Ed.), Developmental Psychopathology. Third Edition Hoboken, NJ: Wiley \& Sons Inc.

Zuckerman, M. (1999). Vulnerability to psychopathology: A biosocial model. Washington, DC: American Psychological Association.

Iro Fragkaki is a $\mathrm{PhD}$ Candidate at Radboud University, Behavioural Science Institute in the Netherlands. She received her Research Master in Clinical and Developmental Psychopathology in 2014 from the VU University. Her major research interests include the development and etiology of antisocial behavior, psychophysiological and neurobiological correlates of psychopathy and externalizing behavior, trauma, and dissociation.

Prof. dr. Maaike Cima is a Professor at Radboud University, Behavioural Science Institute in the Netherlands. Her major research interests include the underline mechanisms as well as the psychophysiological and neurobiological correlates of antisocial behavior and psychopathy in youth, emotional processing and emotional memory in juvenile offenders, and neuro-anatomical correlates of moral emotions.

Dr. Maaike Verhagen is an Assistant Professor at Radboud University, Behavioural Science Institute in the Netherlands. Her major research interests include genetic research in relation to psychopathology, loneliness, emotional processes, and internalizing problems.

Dr. Dominique F. Maciejewski is a postodoctoral researcher at EMGO Institute for Health and Care Research and the VU University Medical Center in the Netherlands. Her major research interests include developmental psychopathology, depression in offspring of parents with mood disorders, and mood variability in adolescents.

Dr. Marco P. Boks is a psychiatrist and researcher at UMC Utrecht in the Netherlands. His major research interests include the gene environment interactions on the development of mental illness and he specialized in epigenetic research.

Prof. dr. Pol A.C. van Lier is a Professor at VU University Amsterdam, Faculty of Behavioural and Movement Sciences, Clinical Developmental Psychology Mental Health in the Netherlands. His major research interests include social relations in adolescence and their influence on the development of psychopathology in children.

Prof. dr. Hans M. Koot is a Professor at VU University Amsterdam, Faculty of Behavioural and Movement Sciences, Clinical 
Developmental Psychology Mental Health in the Netherlands. His major research interests include developmental psychopathology and the development of internalizing and externalizing problems in childhood and adolescence.

Prof. dr. Susan J.T. Branje is a Professor at Utrecht University, Faculty of Social and Behavioural Sciences in the Netherlands. Her major research interests include the development of family and peer relationships in adolescence.

Prof. dr. Wim H. J. Meeus is an Emeritus Professor at Utrecht University and Tilburg University in the Netherlands. His major research interests include adolescent development, family and peer relationships, identity and personality development, and mental health in youth. 